\title{
Specific Characteristics of Head and Neck Squamous Cell Carcinoma in Mures Area
} \author{
Zoltán 4

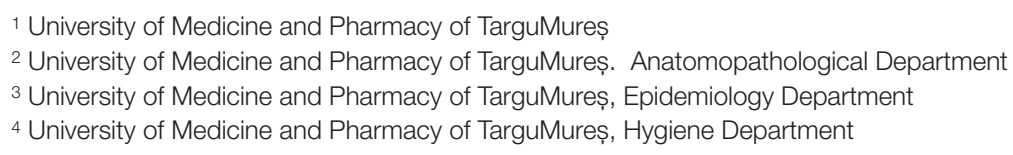

Fejér Enikő Réka1*, Bodi Andrea, Egyed-Zsigmond Imre², Jung loan², Voidăzan Septimiu³, Ábrám

Although head and neck cancers have a rising incidence, these diseases are less investigated because of their localisations' heterogenity. The major risk factors susceptible to influence the evolution of the disease are smoking, alcohol consumption and infection with human papilloma virus. Using data from Mures County Emergency Hospital's histopathology register, we made a retrospective study of 190 cases from the last two years. Factors of interest included age, sex, localization, histopathological subtype and differentiation grade. Median age at diagnosis was 61.31 years, the disease presenting highest incidence in the 51-60 age subgroup and a clear male predominance (5.75:1). The most frequent localization is lower lip (28\%) and the dominant histopathological subtype is cheratinised squamous cell carcinoma (83,8\%) and G2 differentiation grade $(48,1 \%)$. This study supports the finding of increased incidence of cheratinised squamous cell carcinoma in this region. However the literature emphasizes rising incidence of head and neck cancer in younger, we observed that increase in Mures area occurred in 51-60 age group. Lower lip most frequent localization makes possible an early diagnosis.

Keywords: head-neck cancer, squamous cell carcinoma, Mures

Received: 9 December 2014 / Accepted: 4 June 2015

\section{Introduction}

Head and neck cancer (HNC) is considered worldwide a health care problem. Its incidence registrated a $265 \%$ rise in the last 30 years $[1,2]$. In Europe approximately 140,000 new cases of squamous cell carcinoma of the head and neck occur yearly, being associated with mortality rates of 18 and 3 per 100,000 males and females, respectively [3]. More than $90 \%$ have squamous histological subtype and originate from oral cavity or lips [4]. Traditionally this cancer localisation was associated with smoking and alcohol use, but recently Human Papilloma Virus (HPV) has been implicated as a novel risk factor for oropharyngeal carcinoma and appears to be a distinct entity with different biology and clinical outcomes $[5,6]$.

This anatomically inhomogenous, rarely studied cancer is often diagnosed at an advanced stage, where treatment options may not be curative or can have severe posttreatment adverse events [7].

\section{Methods}

We conducted a retrospective analysis of 290 head and neck tumors in Mures County Emergency Hospital's Histopathology Register, including cases fromrecorded in the last two years. Histopathological diagnosis and tumor grade were established accordingly to World Health Organisation Classification of Tumors (IARC 2005) and modified Broders' grading system; 100 patients were ex-

* Correspondence to: Enikő Réka Fejér

E-mail: eniko.fejer@clicknet.ro cluded as having benign proliferation. Baseline data of 190 patients with malignant tumors collected at diagnosis included age, sex, localization, histopathological subtype and differentiation grade.

We used descriptive statistics to characterize the group and evaluated differences in patients characteristicswith two-tailed $X^{2}$ tests. A level of significance (p) of 0.05 was defined as significant.

\section{Results}

\section{Patient characteristics}

The median age was 61.31 years (range 35-93) with homogenous distribution. More than half $(60.3 \%)$ of patients were between 51-70 years at diagnosis (Figure 1). The male-to-female ratio was 5.75 .

The most common histological type was squamous cell carcinoma $(97.88 \%)$, with cheratinised subtype domination (84.24\%). Other histological types, representing $0.53 \%$ of cases, included sarcoma, non Hodgkin lymphoma and undifferentiated forms. Half of cancers were moderately differentiated grade 2 .

The gender distribution in favour of males was the highest in 51-60 years age group.

The most frequent localisations were lower lip 28.04\%, buccal floor 25.93\% and tongue $23.81 \%$ (Figure 2).

We observed that patients aged 51-60 years have mostly buccal floor malignancies and those aged 71-80 years have lower lip cancer (Figure 3.)

Grade 2 tumors were the most frequent located on lower lip and tongue cancers (Figure 4). 


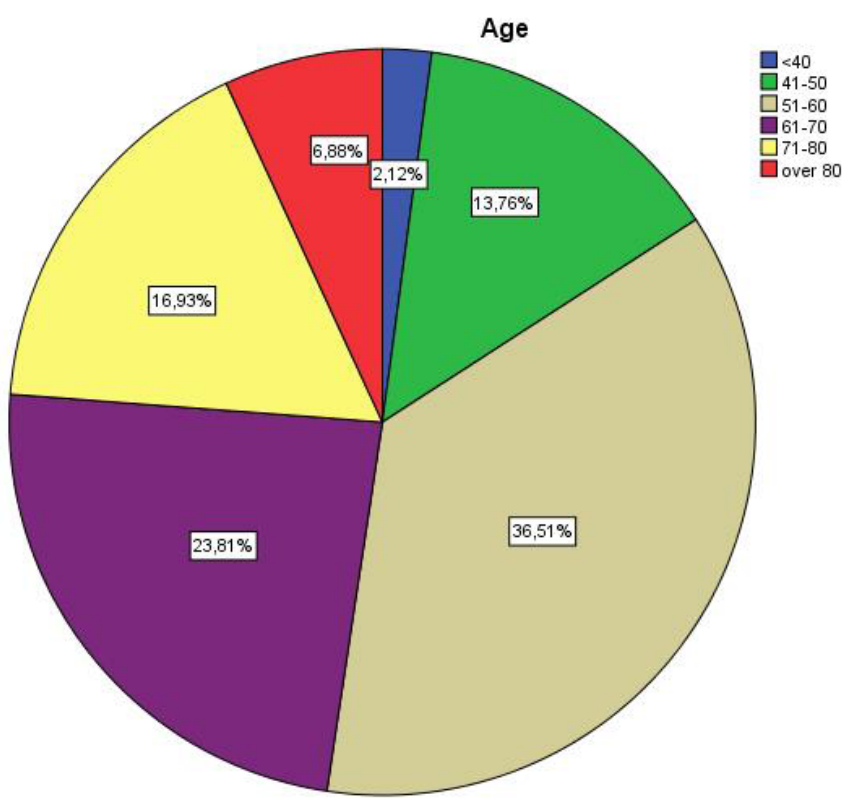

Fig. 1. Head and neck cancers, age at diagnosis

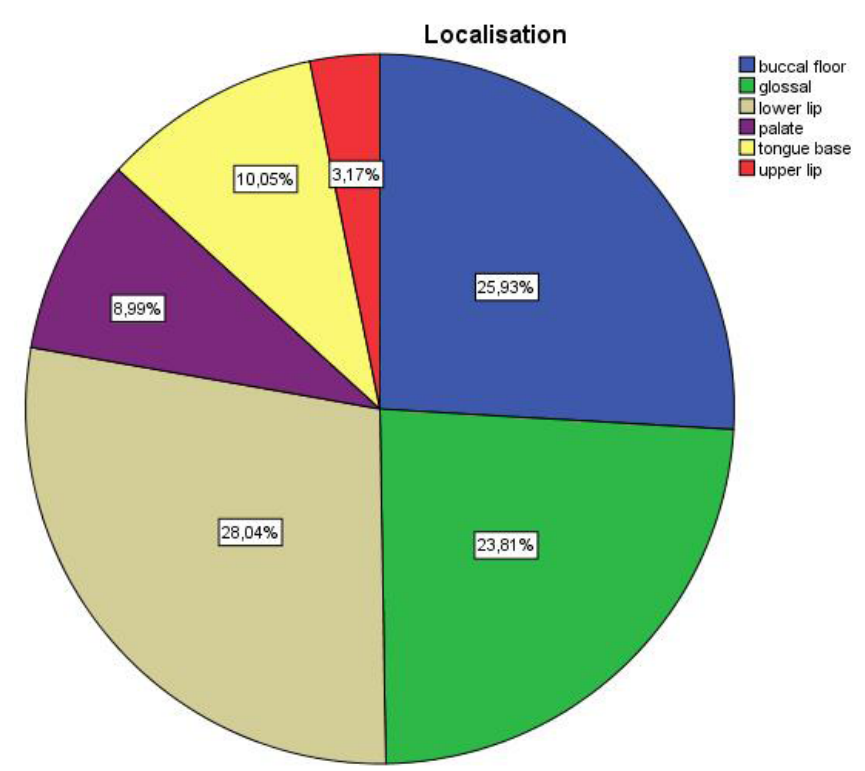

Fig. 2. Localisation pattern of HNSCC

\section{Discussion}

In the present study we demonstrated that in Mures area malignant tumors are diagnosed frequently at advanced ages. Age specific cancer incidence raise sharply from 41-50 years, peaks in the age group 51-60 and subsequently drop steadily; in our study more than half of patients (60.3\%) were 51-70 year-old at diagnosis. European pattern [8] was approximately identical and the peak incidence of HNC was at 50-59 age group, similarly distributed in males and females [9]. In our area we registered a 5.75 fold higher incidence of HNC in men compared with women. In the literature it was difficult to find a homogenous description of this anatomical site, because the anatomy of the head and neck is complex and is divided into sites and subsites, tumors of each site have an unique epidemiology, anatomy, and natural history, and require different therapeutic ap-

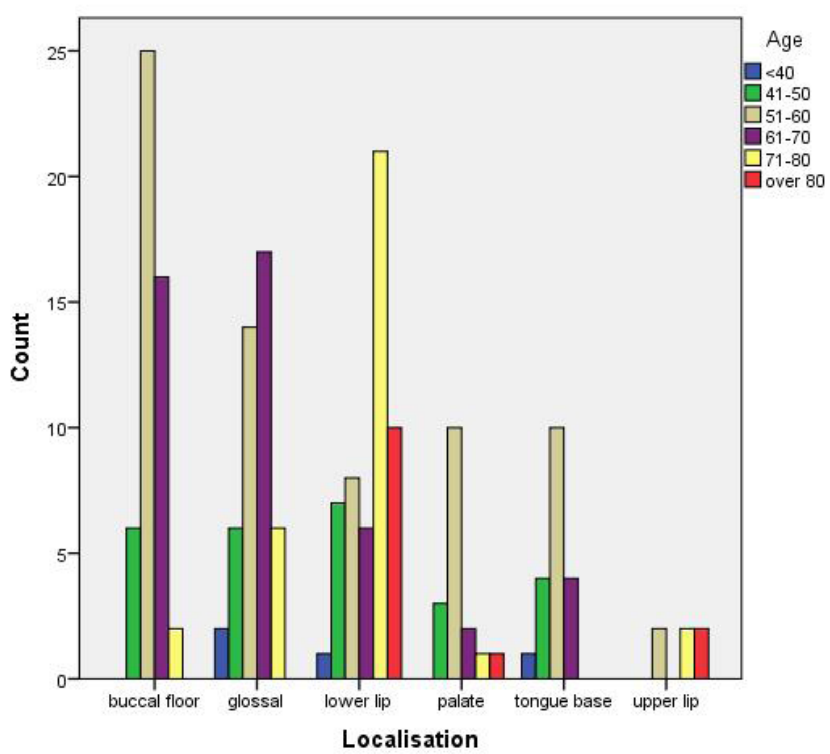

Fig. 3. Age related distribution of HNSCC

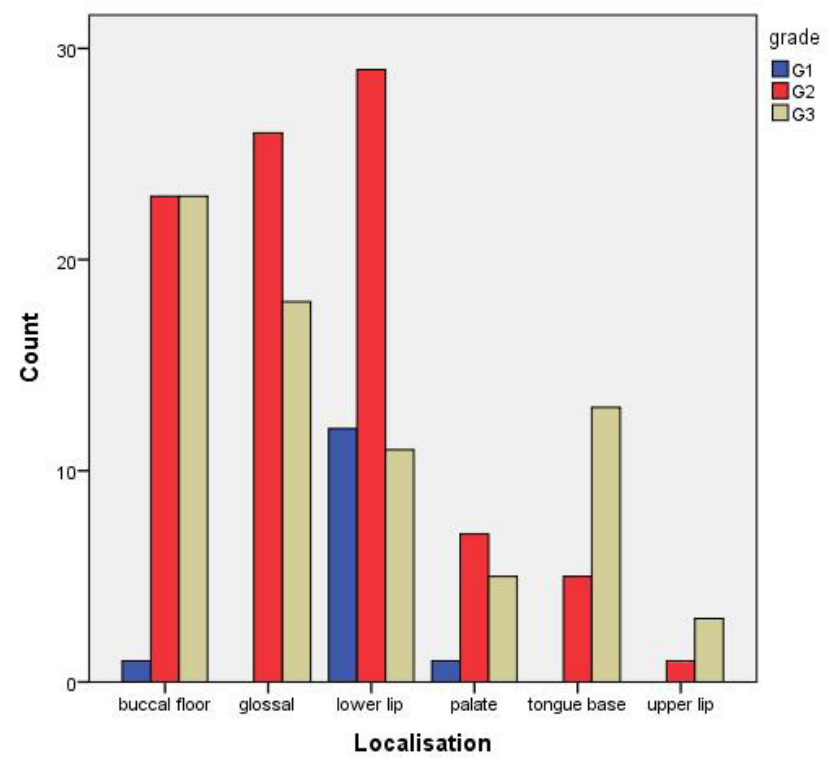

Fig. 4. Histological grade related distribution of HNSCC

proaches. We had no comparison data for the region incidence- trend over time.

Geographical variation in oral cancer reflects the prevalence of well established risk factors, alcohol and smoking. Men excessive smoking and alcohol consumption in deprived areas [10] is related with higher incidence of this malignancy and reduction in alcohol consumption and smoking abandon reduce $\mathrm{HNC}$ incidence and mortality $[11,12]$

Most frequent localisations were different from European pattern, were the incidence of an easily observable lip cancer is consistently reduced to $6.0 \%$, compared to our $31.14 \%$.

The development and clinical use of effective therapies in $\mathrm{HNC}$ will depend on accurate diagnosis of the disease. Classical histopathological and modern molecular tools 
make possible rationale cancer treatment [13]. Therefore evaluation of cellular characteristics, novel predictive biomarkers (kras mutation) for treatment are greatly needed [14].

\section{Conclusion}

This study emphasizes the unusually high incidence of lip cancer in Mures area. An organized education of the population, associated with a direct and complete physical examination could prevent this type of cancer. Key objectives are to raise awareness in the general population and among health care professionals.

There is an urgent need to create and use an organized oncology register, which could permit a real-time patient follow up of these patients.

\section{Acknowledgments}

This paper was published under the frame of European Social Found, Human Resources Development Operational Programme 2007-2013, project no. POSDRU/159/1.5/S/133377

\section{References}

1. Kásler M. Az onkológia alapjai. Medicina, Budapest, 2011;327-386.

2. Stewart B. W., Wild C. P. World Cancer Report. International Agency for Research on Cancer, Lyon 2014;422-431.

3. Gregoire V, Lefebve JL, Licitra A et al. Squamous cell carcinoma of the head and neck: EHNS-ESMO-ESTRO Clinical Practice Guidelines for diagnosis, treatment and follow up. Ann Oncol, 2010;21(suppl 5): v184186.

4. National Comprehensive Cancer Network. NCCN clinical practice guidelines in oncology: head and neck cancers. Version 2.2013

5. Psyrri A, Rampias T, Vermorken JB The current and future impact of human papilloma virus on treatment of squamous cell carcinoma of the head and neck. Ann Oncol 2014; v25 2101-2115.

6. Huang $\mathrm{H}$, Zhang $\mathrm{B}$, Chen $\mathrm{W}$ et al. Human papillomavirus infection and prognostic predictors in patients with oropharyngeal squamous cell carcinoma, Asian Pacific Journal and Cancer Prevention, 2012;13:891896.

7. Reich M, Leemans CR, Vermorken JB, et al. Best practices in the management of the psycho-oncologic aspects of head and neck cancer patients: recommendations from the European Head and Neck Cancer Society Make Sense Campaign. Ann Oncol, 2014;v25 2115-2124.

8. Ferlay J, Steliarova-Foucher E, Lortet-Tieulent J, et al.Cancer incidence and mortality patterns in Europe: Estimates for 40 countries in 2012. European Journal of Cancer, 2013;v49 1374-1403.

9. Parkin DM, Boyd L, Walker LC. The fraction of cancer attributable to lifestyle and environmental factors in the UK in 2010. BJC, 2011;105:7781.

10. Cancer in Wales 1995-2009 A comprehensive report, 2012.

11. Balagopal PG, George NA, Venugopal A. Tobacco related habits among first degree relatives of patients undergoing surgery for advanced head and neck malignancies in India, Asian Pacific Journal of Cancer Prevention, 2012;217-220.

12. Jerjes W, Upile T, Radli $\mathrm{H}$ at al. The effect of tobacco and alcohol and their reduction/cessation on mortality in oral cancer patients: short communication, Head Neck Oncology, 2012; v12 4-6

13. Weinberg RA. The biology of cancer. Garland Science, New York, 2007; 725-796.

14. Chung $\mathrm{CH}$, Lee JW, Slebos RJ et al. A 3'-UTR KRAS variant is associated with cisplatin resistance in patients with recurrent and/or metastatic head and neck squamous carcinoma Ann Oncol, 2014;v25:2230-2236. 